\title{
Practical Research on TBL-teaching Mode in the Sports Biomechanics Course
}

\author{
Chunzhen $\mathrm{He}^{1, \text { a }}$, Jihong Jing ${ }^{1, \mathrm{~b}}$, Yuliang Sun ${ }^{1, \mathrm{c}}$ \\ ${ }^{1}$ School of Physical Education, Shaanxi Normal University, Shaanxi 710119, China; \\ achunbao0822@163.com, b519016085@qq.com, csunsyl123@163.com
}

Keywords: Team Based Learning, Sports Biomechanics, Teaching application.

\begin{abstract}
Based on the application of team-based learning (TBL) teaching mode in sports biomechanics course, this study adopted TBL-teaching method in specific chapters in teaching practice to explore and solve problems in current sports biomechanics course teaching. In this study, the research background, implementation plan, main tasks, implementation and suggestions for improvement of the project are elaborated in detail. Through the study, it was found that this teaching mode was practicable in the teaching of sports biomechanics. This method could improve the teaching effect, enhance the students' participation, enthusiasm and interest in the classroom learning, which was beneficial to the development of the students' overall level. At the same time, as the classroom atmosphere was "overactive", the management of classroom discipline should also be paid attention to in the implementation of the TBL-teaching model in the future.
\end{abstract}

\section{Introduction}

Sports biomechanics is an inter-discipline, by using the mechanics principles and methods to study human movement. Sports biomechanics is a practical course which have high-tech and integrate with the theory and practice, and an important theoretical course of physical education major students [1].

At present, there are some problems in the teaching of physical biomechanics in our country:

1 . The construction of course materials fall behind

The lagging behind in teaching material construction is mainly manifested in the content system, research methods, measurement technology and latest achievements, etc., and the development of backward disciplines and the need of sports practice. The general textbook of sports biomechanics in China was published later. In 1981, the people's sports press officially published the national sports general textbook "sports biomechanics". The development of this discipline is very fast, especially the progress of research methods and measurement technology is changing rapidly. However, the publication period of general textbooks is too long, and the construction of teaching materials is lagging behind.

2. The deficiency of the combination of theory and practice

The development of TBL-teaching mode in our country is still in the initial stage, and TBL-teaching mode is mainly used in the teaching of clinical medicine [2-4]. In front of our school sports biomechanics has analyzed the urgent need to address three aspects of the problem. Sports biomechanics courses not only require students to master the relevant concepts, but also emphasize the practical ability to operate. In this study, the TBL model was applied in the teaching of "Sports biomechanics" to clarify the teaching effect of TBL, trying to improve the existing problems in the teaching of sports biomechanics course and comprehensively understand the experience of TBL application from a student's point of view, to provide the basis for the education reform.

\section{Methods}

Through reviewing a large number of literatures, the purpose of the research was confirmed with the research progress of TBL, and the research contents and schemes were determined according to the characteristics of sports biomechanics curriculum. 
According to the existing literature to determine the questionnaires, we designed questionnaires, designed "Biomechanics" curriculum feedback evaluation table to evaluate the teaching effectiveness. In this study, students of 4 classes of PE education in 2015 were selected as the survey subjects, and TBL-teaching design was conducted by using "sports biomechanics" of the second grade in 2016-2017 school year. Specific course design includes:

1. Divided into teams according to the "Sports Learning and Control" final results (these two courses have a certain common), every 4-5 students as a team. In consideration of the project cycle, funding and college curriculum arrangements in the teaching of sports biomechanics, we will select a specific chapter of the TBL-teaching model design;

2. We arranged the preview for the classes before one week and urged the leader to organize team members to learn and inform students that individual and team tests will be conducted in class;

3. For individual testing, team testing and practical exercises in the classroom:

Individual Test: The title is relatively simple and provide the correct answer. To help students master the theoretical knowledge.

Team Test: Make team discussion, scratch card, and select the team answer. The answer is correct, then scratch the layer visible symbol tips; answer wrong, scratch the layer unsigned tips.4 points for each problem, each scratch a wrong button deduction of one point.

Practical Exercises: Use team exercises to solve practical exercises. Teacher observes and guides students.

4. Student Feedback: Each team solved the problem in the study, the teachers were walking to answer the questions;

5. The teachers had a guide which the issues and practice in classroom;

6. Use of "4S" ("significant" problem, groups work on the "Same" problem at a given time, "specific" choice, "simultaneous" report);

7. Encourage students to discuss;

8. Students completed the questionnaires to reflect the teaching effectiveness. A total of 78 questionnaires was gathered, with 76 valid ones.

\section{Results}

There are 14 questions in questionnaires and include 12 multiple-choice questions and two open-ended questions. The article mainly analyzes the following five representative issues.

TBL-teaching mode can fully mobilize students' enthusiasm for learning, $48.7 \%$ of students totally agreed with TBL-teaching mode in mobilizing students' enthusiasm, $44.7 \%$ of students agreed basically, but $6.6 \%$ of students thought TBL-teaching mode didn't have effect in mobilizing students' enthusiasm (Table 1).

Table 1 The degree of TBL-teaching to motivate the students motivation ( $\mathrm{n}=76$ )

\begin{tabular}{cccccc}
\hline Fully agree & $\begin{array}{c}\text { Basic } \\
\text { approval }\end{array}$ & Not clear & $\begin{array}{c}\text { Basically do } \\
\text { not agree }\end{array}$ & $\begin{array}{c}\text { Totally } \\
\text { disagree }\end{array}$ & Abstain \\
\hline $48.7 \%$ & $44.7 \%$ & $6.6 \%$ & $0 \%$ & $0 \%$ & $0 \%$ \\
\hline
\end{tabular}

TBL-teaching is a teaching mode based on the team as a unit, which can guarantee the quality of class, and cultivating students' sense of teamwork. As can be seen from Table 2, $44.7 \%$ of the students experienced the cooperation between the team members and agreed the TBL-teaching model could enhance students' awareness of the team completely; $50.0 \%$ of students basically agreed; $5.3 \%$ of the students of no practical felt the cooperation between the team, and not clear TBL-teaching mode could improve students 'sense of teamwork, developed students' ability of teamwork and improved learning efficiency. 
Table 2 TBL-teaching model can enhance student's team awareness $(\mathrm{n}=76)$

\begin{tabular}{cccccc}
\hline Fully agree & $\begin{array}{c}\text { Basic } \\
\text { approval }\end{array}$ & Not clear & $\begin{array}{c}\text { Basically do } \\
\text { not agree }\end{array}$ & $\begin{array}{c}\text { Totally } \\
\text { disagree }\end{array}$ & Abstain \\
\hline $44.7 \%$ & $50.0 \%$ & $5.3 \%$ & $0 \%$ & $0 \%$ & $0 \%$ \\
\hline
\end{tabular}

As can be seen from Table 3, 60.5\% of the students in the classroom felt deeply that they agreed fully with the TBL-teaching mode could make the classroom atmosphere more actively; 38.2\% of students basically agreed; $1.3 \%$ of students felt not obvious and not clear. Some scholars have also proposed that TBL-teaching mode is different from the traditional class mode, instead of the traditional teacher teaching in the form of team cooperation, the "rigid" teaching mode accepted by students can make the classroom atmosphere more active.

Table 3 TBL-teaching modality to make classroom atmosphere more active $(\mathrm{n}=76)$

\begin{tabular}{cccccc}
\hline Fully agree & $\begin{array}{c}\text { Basic } \\
\text { approval }\end{array}$ & Not clear & $\begin{array}{c}\text { Basically do } \\
\text { not agree }\end{array}$ & $\begin{array}{c}\text { Totally } \\
\text { disagree }\end{array}$ & Abstain \\
\hline $60.5 \%$ & $38.2 \%$ & $1.3 \%$ & $0 \%$ & $0 \%$ & $0 \%$ \\
\hline
\end{tabular}

According to the data statistics, 38.2\% of students agreed fully that using TBL-teaching mode would be more concentrated in class; $46 \%$ of students basically agreed; and $14.5 \%$ of students thought TBL-teaching mode was not obvious in making student spirit more concentrated. 1.3\% students basically disagreed (Table 4). Students experienced different from the traditional teaching mode. More learning fun and more energy in the classroom, and fully mobilize the enthusiasm of students learning. In the class, students' energy can be more focused.

Table 4 Students who have more concentration in the class by use TBL-teaching mode $(\mathrm{n}=76)$

\begin{tabular}{cccccc}
\hline Fully agree & $\begin{array}{c}\text { Basic } \\
\text { approval }\end{array}$ & Not clear & $\begin{array}{c}\text { Basically do not } \\
\text { agree }\end{array}$ & $\begin{array}{c}\text { Totally } \\
\text { disagree }\end{array}$ & Abstain \\
\hline $38.2 \%$ & $46 \%$ & $14.5 \%$ & $1.3 \%$ & $0 \%$ & $0 \%$ \\
\hline
\end{tabular}

TBL-teaching mode allowed students through the exchange of learning between teams, found problems and solving problems, also improves the ability of students' interpersonal skills. $39.5 \%$ of students fully agreed the effect; $51.3 \%$ of students basically agreed with this point of view; $9.2 \%$ of students without deep experience and didn' t clear about it. The TBL-teaching model had a positive impact on student interpersonal communication and could improve students' communication skills, which was consistent with the characteristics of the innovative teaching model (Table 5).

Table 5 TBL-teaching model can improve students' interpersonal skills ( $\mathrm{n}=76$ )

\begin{tabular}{cccccc}
\hline Fully agree & $\begin{array}{c}\text { Basic } \\
\text { approval }\end{array}$ & Not clear & $\begin{array}{c}\text { Basically do } \\
\text { not agree }\end{array}$ & $\begin{array}{c}\text { Totally } \\
\text { disagree }\end{array}$ & Abstain \\
\hline $39.5 \%$ & $51.3 \%$ & $9.2 \%$ & $1.3 \%$ & $0 \%$ & $0 \%$ \\
\hline
\end{tabular}

Through the analysis of the questionnaire, it is concluded that most of the students are supportive the TBL, which can fully arouse students' enthusiasm for learning. However, the classroom order in the course could not be well maintained and some links in the classroom were rather chaotic. During the exchange of questions, some students found it hard to found a solution to the problem. While 
arousing the enthusiasm of most of the students, there was still a small part of their classmates' attitudes Positive, over-reliance on other students in the team.

The students' opinions and suggestions on TBL-teaching mainly include: 1.During the distribution and transfer, a plan must be to maintain the order in the team; 2.The grouping must take into account the personality differences of the team members; 3.The tasks of the members should be specific to each member.

\section{Conclusion}

Through this study, it is feasible to adopt the TBL-teaching mode in sports biomechanical courses. It can fully mobilize the enthusiasm of students in class so that more students go into the curriculum and master the knowledge in the discussion. It broke the traditional teaching methods and with a high degree of innovation, students have higher degree of recognition of the TBL-teaching model. Through cooperative learning in the team, students improve their enthusiasm for learning and put more energy into learning problems in the team. [5-7].It also can promote pre-class study and classroom efficiency. TBL-teaching mode has given full play to its own teaching role and enhanced students' sense of teamwork. TBL-teaching mode can help students establish self-learning concept of learning, while cultivating the awareness of student teamwork, but also promote the independent learning ability of students and effectively improve the efficiency of teachers. Compared with traditional teaching methods, TBL-teaching mode can make classroom atmosphere more actively and let more students participate in the course. The TBL-teaching mode is a form of taking classes based on a team, $90.7 \%$ of the students experience the teamwork advantage of the TBL-teaching mode in their study, which increases the fun of the class and reduces the tedium of the class. Students' experience is different from the traditional teaching mode, giving more learn energy in the classroom and TBL-teaching mode makes more students participate in it.

Therefore, we should pay attention to the management of the classroom discipline and ensure the order in the classroom in the future. While encouraging the students who are actively participate in the class, we also need to pay more attention to the enthusiasm of the minority students in the class and make more students participate in the classroom.

When grouping, we must take full account of the characteristics of each student and make the teaching group more reasonable. To take care of every student in the classroom fully, we avoid the emergence of "extreme" phenomenon.

\section{References}

[1] Xiuyuan Zheng: Modern sports biomechanics. National Defense Industry Press, 2007.

[2] Chuanlai Zhang: Application of Group Cooperative Learning in Clinical Nursing Teaching in ICU. Chinese Journal of Medical Education.2009, 8(3):239-241.

[3] Lili Wang, Qiuyue An, Shuangli Huang,etc:Application and Effect of Cooperative Learning Theory in Community Nursing Teaching. Nursing Management Magazine 2009, 9(3):44-45.

[4] Zheng Lin, Ping Gu, Guozhen Sun,etc:Application of group cooperation learning mode in nursing pedagogy practice teaching. Chinese nursing education2009, 6(6):253-254.

[5] Michaelsen L K, Schultheiss E E:Making Feedback Helpful. Journal of Management Education 1989, 13(1):109-113.

[6] Parmelee D X, Michaelsen L K:Twelve tips for doing effective Team-Based Learning (TBL).Medical Teacher2010, 32(2):118-22.

[7] Kelly P A, Haidet P, Schneider V, et al: A comparison of in-class learner engagement across lecture, problem-based learning, and team learning using the STROBE classroom observation tool. Teaching and Learning in Medicine 2005, 17(2):112-8. 